\title{
进退维谷一香港公营房屋政策的困境与挑战
}

\section{Be in a Dilemma: The Difficulties and Challenges of Public Housing Policy in Hong Kong}

\begin{abstract}
摘要: 基于对香港公营房屋建设与发展历程回顾, 着重分析了香港公营房屋政 策演进及其面临的困境与挑战。尽管香港庞大的公营房屋规模获得了“扶贫” 的美誉, 但有关严控土地供应与 “稳定楼市” 等政策而助推的高房价, 也常被 批评为政府与地产霸权共谋而形成的畸形增长机器下的产物。而公营房屋也由 于“早期居住条件恶劣需要推倒重建” 以及存在严苛的转让限制, 不仅导致可 观的资源浪费与社会效率损失, 也致使大量居民被“㨡绑”在公营房屋内成为 另类“房奴”, 由此衍生的“双元城市”与 “悲情市镇”不能不说是房屋政策 惯性下的“副产品”。此外, 在香港回归后日益泛政治化的约束下, 受各方角 力与牵制的香港房屋政策一直襄足不前, “退后一步是泥淖, 往前一步可能是 陷吽”。香港公营房屋所积累的结构性问题正面临进退维谷的困境。
\end{abstract}

Abstract: Based on the reviews of Hong Kong's public housing construction and development, this paper emphatically analyzes the difficulties and challenges in the evolution of Hong Kong's public housing policy and faces. Despite the sheer scale of public housing in Hong Kong have been obtained in "poverty alleviation" reputation, the high price of house, which boosted by policies such as strict control of land supply and "stabilize the housing market", are criticized as a product of abnormal growth machine that conspired and formed by the government and the estate hegemony. The existences of public housing that "need to be turn down due to early poor living conditions" and the strict transfer limit, not only lead to considerable waste of resources and social efficiency loss, also make a large number of residents "bundled" become the alternative "mortgage slave" in public housing . The derivatives of "dual city" and "tragic town" have to be said as "by-product" under the housing policy inertia. In addition, under the constraint of the increasingly "Pan political" after the return of Hong Kong, the housing policy in Hong Kong which was wrestled with contain by the parties has been stalled. "Step back is a morass, step forward may also be a trap" . Structural problems accumulated by Hong Kong public housing is confronting with a dilemma situation.

关键词：香港；公营房屋；公屋；居屋计划

Keywords: Hong Kong; Public Housing; Public Rental Housing; Home Ownership Scheme

\section{1 回归前港英政府的公营房屋 : 从被动应对 到积极干预}

\section{1 “徙置计划”与 “十年建屋计划”}

香港公营房屋 ${ }^{1}$ 建设可追溯至 1950 年代因寮屋 (squatter unit) (2) 火灾频发而着手的被动干预。由 于特殊的地缘政治形势, 二战以及随后的国内内战 引发了大量内地难民流向香港, 致使香港人口激增。 1945-1951 年间, 香港人口由 60 万渀升至 230 万 ${ }^{[1]}$, 导致对住房的需求陡升, 不仅市区内旧楼挤满了内地 移民和港人，市区边缘也逐渐被 “违法搭建” 的寮屋 所占据。为遏制租金暴涨以稳定局势, 港英政府于 1947 年实施租务管制, 严格限制租金与禁止逼迁, 致 使市区旧楼无法拆除重建, 进一步加剧了市区边缘寮 屋区的林立 ${ }^{[2,3]}$ 。1953 年圣诞夜发生的石硖尾寮屋区 大火，造成 5.3 万灾民无家可归，迫使港英政府 “火 速” 启动安置寮屋难民的“徙置计划” (Resettlement Programme), 可说是香港房屋政策的肇始 ${ }^{[4]}$ 。

为化解寮屋区频发的火灾危险和对公共卫生及秩 序造成的威胁, 临时决策的 “徙置计划” 主要是为清 拆寮屋, 并为受影响的移民提供暂时性住所 ${ }^{[5]}$, 其目 标是短期内兴建足够数量的 “徙置大厦”。“量的提供 而非质的保证” “6], 使得早期的徙置大厦建造标准极低, 每个成年人可使用面积仅 $2.2 \mathrm{~m}^{2}, 10$ 岁以下儿童低至 $1.1 \mathrm{~m}^{2}$ 。住房内不仅无水电供应, 还缺少基本的生活

\footnotetext{
作者: 魏成, 博士, 华南理工大学建筑学院、亚热带建筑科学国家重点实验室, 副教授, 硕士生导师。weicheng@scut.edu.cn. 李骁, 硕士, 云南省设计院集团

赖亚妮, 博士, 深圳大学土木工程学院建设管理与房地产系, 讲师

(1) 公营房屋是香港公共房屋的总称,包括公共租住房屋(简称公屋,相当于内地的廉租房) 和 “居者有其屋” (简称居屋,相当于内地的经济适用房)。

(2) 寮屋即木屋, 这里指低质量的非法搭建房屋。
} 
设施，仅在中央走廊设置公用的洗衣、则所和冲凉设施（直 到 1962 年的徙置大厦才配有独立厨则） ${ }^{[3,7]}$ 。1964 年, 港英 政府才对市区居民放宽人住资格，从而使得 “徙置大厦”真 正具有了城市公共住宅属性。1954-1973 年 “徙置计划” 终结时的 20 年间, 港英政府共建成 500 多幢大厦, 为超过 100 万人提供了居所。但 “徙置大厦”也被批评为品质低劣, 不仅落后于香港当时的生活水平 ${ }^{[5]}$, 更无法满足未来需要 ${ }^{[8]}$ 。

1960 年代开始, 香港经济迅速成长, 由此要求改善 居住环境的呼声也愈加强烈 ${ }^{[9]}$, 而在财政逐渐充实的情形 下，港英政府也逐渐意识到改善民生、缓和社会矛盾对政 局稳定和经济增长的重要性。1972 年, 时任港督的麦理浩

(Murray MacLehose) 推出 “十年建屋计划” (TYHP: TenYear Housing Programme), 标志着香港公屋政策由主要安置 灾民转向致力于为低收人居民提供住所, 为香港公营房屋的 架构和发展奠定了重要基础。TYHP 的目标是在 10 年内为 180 万香港居民提供公屋。为推进 TYHP, 港英政府于 1973 年整合相关机构成立独立的公营房屋主管部门一一香港房屋 委员会 (简称房委会), 以全面统筹香港的公营房屋建设和 发展。

经过 10 年的努力, TYHP 约为 100 万人提供了租住居 所, 对于改善香港居住条件产生了重要的促进作用。1982 年, 香港决定将 TYHP 顺延五年以完成尚未达成的建屋目标。 TYHP 的一项显著成绩是利用公营房屋建设推动市区外围新 界 “新市镇” 的快速发展 (如荃湾、沙田、屯门等), 公屋 与新市镇的发展保持着紧密的联系 ${ }^{[10,11]}$ 。相对较短的轮候时 间与较低的租金, 吸引市区人口加速向新界地区迁移。新界 居民占全港人口的比例也由 1971 年的 $18.9 \%$, 上升到 1981 年的 $23.2 \%$ 。

\section{2 “居者有其屋”与 “长远房屋政策”}

尽管 “十年建屋计划” 成绩显著, 但由于其推行的是 “公租房”, 因此无法照顾到那些 “条件不够人住公屋, 又 缺乏足够经济能力自置楼宇或缴付昂贵租金的“夹心阶 层'” ${ }^{[3,12]}$ 。基于居民收人的增长以及自置居所的需求高涨, 1976 年港英政府推出 “居者有其屋（简称居屋）计划”

(HOS: Home Ownership Scheme), 并随后于 1978 年推出 “私人机构参建居屋计划” (PSPS: Private Sector Participation Scheme), 鼓励私营开发商参与居屋建设。香港房委会负责 居屋的选址、设计、开发和出售。居屋通常免地价, 以低于 市场价 30\% 50\% 左右出售给符合条件的居民 ${ }^{1}$ 。虽然 HOS
和 PSPS 深受市民欢迎, 但其建设规模并不算大-19801987 年间, 居屋平均年建设量约 1 万套左右, 公营房屋政 策的重点仍是公屋 ${ }^{[13]}$ 。

经过近 30 年的建设, 至 1980 年代中期, 香港已告别了 夕日的房荒, 房委会已拥有当时世界上最大量的公共住房, 成为世界级的 “大业主”, 有超过 240 万人居住在公营房屋, 占全港人口的 $45 \%{ }^{[14]}$ 。为充分预估未来人口发展趋势和房屋 需求, 港英政府于 1987 年全面检讨房屋政策, 并发表了一 份计划至 2001 年的长远房屋策略报告。报告确立了房屋以 私人楼宇供应为主导, 政府除继续修建公屋和居屋外, 其政 策扶持方式从供给面转向需求面, 即通过提供优惠贷款协助 市民在私人市场自置居所, 作为长远解决房屋问题的方法, 逐步减轻政府提供公共住房的负担。为配合长远房屋策略, 房委会一方面推出 “整体重建计划” 以逐步拆除重建 566 栋 1973 年以前建成的徙置大厦; 另一方面也推出 “自置居所贷 款计划”, 以协助符合条件的家庭在私人市场自置居所。同时, 房委会也于 1988 年改组, 港英政府与房委会订立了新的财 务安排, 政府注资形式正式退出, 房委会从而成为自负盈亏 的独立机构 ${ }^{[15]}$ 。

至 1990 年代初期, 香港逐步形成了公营房屋和私营住 房并存且平分秋色的格局, 香港被誉为 “世界上解决低收人 者住房的一个成功范例”。截至 1997 年底, 约有 86.9 万户 居民居于公屋和资助出售居所, 约占全港住户总数的 $45 \%$, 自置居所比率由 1971 年的 $18 \%$ 左右, 大幅增至 1997 年的 $52 \%$ 。毫无疑问, 政府已成为香港房屋最重要的生产者和提 供者, 维系着近半数人口的居住需要。其中, 公屋担负了为 低收人阶层提供租住房屋的使命, 而居屋既为缺乏经济能 力于私人市场置业的人士提供资助自置居所, 也让经济条件 逐步改善的公屋租户有途径沿房屋阶梯攀升, 以使其腾出的

“公租房”得以重新编配于最需要的人士。

\section{2 回归后特区政府的公营房屋 : 重新定位与居屋 的重启}

尽管经过数十年的努力, 香港较成功地解决了中低收人 家庭的基本住房问题, 但随着香港未来的逐步明晰, 外来投 资持续不断地涌人香港, 房地产市场成为 “投资者的乐园”, 来势汹汹的中外投资者不断推高香港楼市价格。在 1997 年香 港回归前夕, 楼价与租金的不断上涨, 导致炒卖房地产成风。 住房价格的持高不下造成置业难的声音不绝于耳, 而多年积 压在公营房屋建设中的问题与争议也使政府压力陡增。

(1) 由于居屋用地也是政府无偿划拨的, 为确保公共资源得到妥善利用, 防止投机行为, 香港采取两项控制措施: 其一, 严格审查购房资格, 如家 庭收入、人口数量等; 其二, 居屋的租售等行为受到严苛的转让限制, 详见后文。 
面对迫切的社会需求, 回归后的特区政府及时检讨和更 新“长远房屋策略”, 并于 1998 年 2 月发表《建屋安民、迈 向 21 世纪: 香港长远房屋策略白皮书》。白皮书以行政长官 董建华首份施政报告为基础, 重申香港公营房屋的目标是帮 助所有家庭人住合适和可以负担的住房, 以及鼓励市民自 置居所。白皮书建议措施包括有效监测房屋供求, 改善房 屋供给效率, 缩短市民轮候公屋时间, 以及提高公营房屋 的流动性等。白皮书承诺的目标包括：(1) 每年兴建不少 于 85000 个公营及私营住宅单位（俗称 “八万五”计划）;

（2）在 2007 年或之前提升自置居所家庭的比率至 70\% ; 以及

(3) 在 2005 年或之前把轮候公屋的平均时间由 6 年半缩短 至 3 年。

这份“宏伟”的房屋发展计划受到民众的普遍认可。为 推动自置居所比率, 1998 年, 房委会也顺势推出“租者置 其屋计划”, 以让公屋租户有机会以优惠价格购买现租单位。 然而, 回归后的香港经济环境突然急转直下, “八万五” 计 划生不逢时, 在亚洲金融风暴的冲击下, 私人楼宇价格不断 下滑, 居屋市场价格与私人楼宇价格开始重叠, 市民对居 屋的需求大幅减少。2001-2002 年建成的居屋单位仍有部 分空置, 认购率更跌至历史新低, 居屋的存在价值受到地产 商以及相关社会人士的普遍质疑。随着楼市的恶化, 为避免

“八万五”计划影响楼市, 稳定楼市也成为 1998 年后特区 政府土地及房屋政策的重点, “八万五” 建屋目标无疾而终。

2002 年 11 月, 房屋及规划地政局局长孙明扬发表房屋 政策声明, 强调政府今后的主要角色集中在供应土地以及提 供租住房屋资助两方面, 并退出作为住房发展商的角色。除 出售少量剩余及回购的单位于合资格居民外, 自 2003 年起 无限期停建和停售居屋, 至于已落成和兴建中的居屋, 则会 在不与私人市场直接竞争的原则下改作其他用途, 并终止在

“租者置其屋计划”下出售公屋。声明表明, 特区政府在公 共房屋供给上由直接提供实物变为辅助者 ${ }^{[15]}$, 预示着香港自 1970 年代起所形成的在公屋供给上扮演积极干预角色的瓦 解。曾荫权担任特首的 2005-2011 年间, 香港政府的房屋 政策显得异常谨慎与保守, 即使在 2004 年始香港楼市开始 复苏, 特区政府也未有足够的应对措施, 公营房屋的供应量 大幅回落, 居屋计划由此一直搁置至曾荫权任内的最后一份 施政报告才复提起。

然而, 在 2008 年全球金融危机及其随后的“量化宽松” 金融政策影响下, 香港楼市“扶摇直上” 并迅速超过 1997 年的 “波峰”迈至历史最高位。针对新时期的楼市炽热,
公营及私人房屋的供求均出现的严重失衡, 以及市民极为 关注的房屋问题，特区政府逐步实施一系列短中期政策措 施, 包括设立买家印花税和提高额外印花税、“港人港地” 等 “辣招”，但短期抑制成效十分有限。第三任香港特首梁 振英在 2013 年的首份施政报告中申明 “解决房屋问题, 是 政府的首要任务”, 政府会坚持 “协助基层上楼、协助中产 置业” 的施政理念, 以加快公营房屋的供应。2014 年 12 月 特区政府发布“长远房屋策略”, 提出兴建 48 万套住房单 位作为自 2015/2016 年度起 10 年内的总房屋供应目标, 并 且公私营房屋供应比例确定为 $6: 4$, 明确新时期的房屋策略 是稳中求变, 定期更新长远房屋需求, 以适应不断变化的 社会经济环境。

\section{3 香港公营房屋面临的困境与问题}

香港公营房屋尽管为庞大的中低收人家庭提供可住居 所, 取得了所谓 “社会福利” 的美誉, 但在香港公营房屋发 展进程中, 也日渐暴露了公营房屋计划所面临的困境与问题。 不仅 “地产霸权” 与土地收人直接影响公营房屋政策, 也致 使 “双元城市”引发社会结构的失衡, 特别是庞大的公营房 屋由于存在 “转让限制”, 致使整体社会效率受损, 对于香 港长远发展具有深远的影响。

\section{1 “地产霸权” 约束下的 “供给失衡”}

众所周知, 高度投机的房地产市场对香港经济与房屋政 策产生了巨大影响。香港住房价格的持高不下与房屋供给的 结构性失衡虽发作于回归之后, 病根却可追溯至 1984 年《中 英联合声明》 ${ }^{[16]}$ 。声明规定港英政府于过渡期内（1985 年 5 月 27 日一-1997 年 6 月 30 日）将每年新批土地限于 $50 \mathrm{hm}^{2}$ 以内 (不包括建造公营房屋所用土地), 初衷是中国担忧英 方超量出售土地。然而这一规定客观上却也限制了香港的土 地供应, 成为房价长期上升的基础。香港房价从 1986 年到 1997 年保持着年均 $23.08 \%$ 的增速 ${ }^{[17]}$ 。与此同时, 华资地产 集团在此段时期内逐步取代英资集团, 在极为有限的土地出 让规模制约下, 形成了以 “六大家族” 为主的地产财团, 垄 断利润大得惊人 ${ }^{11}{ }^{[18]}$ 。这些大型地产财团不仅在香港房地产 市场中 “呼风唤雨” 取得绝对控制力, 也逐步涉足物业租 赁及零售、公用事业、电讯事业、交通运输及大型基建等多 元领域, 从而拥有足够实力建立香港版的 “都市增长机器”, 以至于影响政府的决策方向 ${ }^{[4,19]}$ 。

1980 年代初, 香港各种有关土地的收人超过政府总收

(1) 1996 年受政府委托的消费者委员会调查报告发现，1991-1994 年间，香港有 $3 / 4$ 的新私人住宅仅由 10 个开发商提供，且 $55 \%$ 来自四个最大 的开发商。其开发利润也大得吓人, 加上土地在内的所有开发成本, 最低利润是 $77 \%$, 最高利润为 $364 \%$ 。参见参考文献 [18]。 
人的 $1 / 3$ 。而 1990 年代以来与土地交易及开发管理有关的 广义政府收人（包含酒店房租税、物业及投资、公用事业及 与基本工程储备基金有关的债券收人等)，在回归前平均占 政府年度总收人近 $20 \%$, 回归后更有多年突破 $20 \%$, 其中 1997/98，1999/2000，2004/05 等三个财政年度都高居 30\% 上下, 可见土地相关收人在港府财政中扮演了重要角色 ${ }^{[4]}$ 。 1998 年, 香港成为亚洲金融危机的重灾区, 房价从 1997 年 当时历史最高点迅速下跌近六成, 不断减弱的房地产市场也 严重影响了仰赖土地收人的政府财政。香港 2002/2003 年度 财政综合赤字高达 700 亿港元，非经常性收人较原来预算减 少 291 亿港元 ${ }^{[20]}$ 。

为防止楼市进一步下跌, 特区政府被迫于 1998 年 7 月 暂停卖地, 并以 “居屋政策已不再切合市民的需要” 为由, 于 2001 年 9 月实施停售居屋 10 个月。 2002 年 11 月, 房屋 及规划地政局局长孙明扬的房屋声明, 为港府房屋政策作出 全面的重新定位，包括：取消所有原定的土地拍卖，2004 年始只会通过 “勾地” 11 方式出售; 并自 2003 年起无期限 停售停建居屋以及终止 “租置计划” 等, 以至于完全偏离 了既有房屋政策的运行轨迹。自此之后的香港房屋政策显 得十分谨慎与保守, 对整个香港公营房屋的发展具有深远 的影响。

随后, 内地与香港签订《关于建立更紧密经贸关系的安 排》（CEPA）协议, 陆续启动内地居民来港自由行, 大量内 地居民赴港置业, 香港经济得以迅速恢复 ${ }^{[17]}$ 。同时, 在港元 与美元挂钩的联系汇率推波助澜下, 香港房地产市场也深受 全球利率与资本流动的影响。自 2004 年起, 香港私人楼宇 价格开始回升，私人楼宇售价指数已从 2003 年谷底的 61.6 快速上升至 2010 年的 150.9 以及 2013 年的 242.4 (图 1), 房价自 2003 年以来升幅近 4 倍, 私人住宅楼宇的价格已远 超一般家庭所能负担的水平, 2013 年平均房价高达每平方米 12.6 万港元, 激增到全球最高的水平。但自 2002 年至 2013 年底的 12 年间, 香港政府除了间断推出之前尚未出售的少 量居屋单位外, 新落成的居屋量为零, 公营房屋新建成的数 量也由 1997-2002 年的平均近 4 万套，到 2003-2013 年间 大幅减少至平均不到 1.6 万套 (图 2)。在香港人口持续增长 的现实条件下 (人口由 2002 年的 678.7 万人增长至 2013 年 的 718.7 万人, 年均增长约 3.6 万人), 公屋轮候人数也不断 增加（截至 2014 年 6 月, 公屋轮候册人数已突破 25 万人), 而申请购买居屋的人数也远超待出售居屋的数量。
由于香港被视为特殊的 “地产国度” (property state) ${ }^{[21]}$, 土地成为政府的根本生财之道, 土地在地狭人稠的香港属于 珍贵资源,做关土地开发的房屋政策向来是都市政策重点 ${ }^{[22]}$ 。 在“土地就是权力” 的约束下 ${ }^{[18]}$, 围绕土地与房屋供给所产 生的 “地产霸权” 在都市政治上扮演关键角色, 香港房屋政 策的裂变也由此与其经济结构的复杂关系缠绕在一起。因此, 香港公共房屋建设指标越来越被视为规制、刺激和调节房地 产市场的工具, 香港房屋失衡问题的根源在于由一个难以驾 驭的结构性缺陷所左右 ${ }^{[23]}$ 。

\section{2 “转让限制” 影响下的 “效率损失” 与社会代价}

经过近 60 年的建设与积累, 截至 2013 年, 香港公共租 住房屋共约 77 万套, 居住人口 210.6 万; 资助自置居所约 39 万套, 居住人口 118.6 万; 公营房屋累计约 116 万套, 居 于公营房屋人口约 329 万, 占全港人口总数的 $45.8 \%$ （表 1)。 尽管庞大的公营房屋赢得了 “扶贫” 的美誉, 但其仍只限于 让市民 “有瓦遮头”。由于不能在市场上自由租售, 因此无 法 “物尽其用”, 导致无法充分发挥其土地效益, 公营房屋 的价值也就 “蒸发于无形” [24]。

对于公屋而言, 经过严格的家庭人息、家庭人数等条件

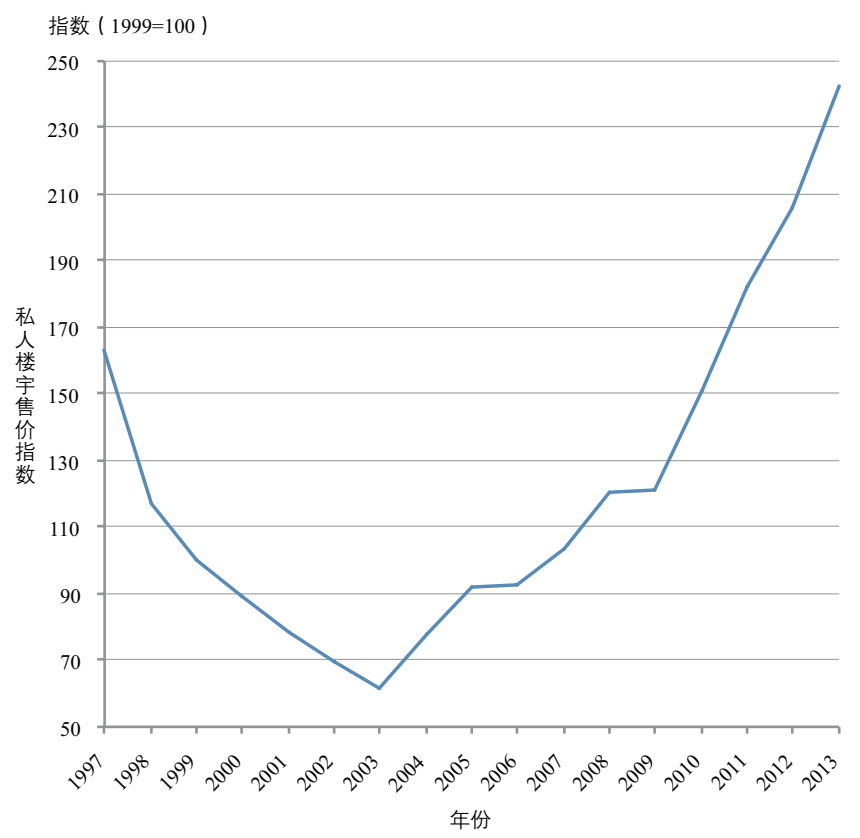

图 1 1997-2013 年的私人楼宇价格指数变化图 资料来源 : 根据各年香港统计年刊绘制

(1) “勾地政策” 是指香港为保证土地出让的价格符合政府预期, 在拍卖土地前增加 “保险程序”: 香港地政总署定期列出公开的土地储备表 (勾地表), 如有开发商看中其中的某个地块, 可向土地管理部门提出申请, 报出一个底价, 政府管理部门如认为符合市场估价, 就将这块地按规定“勾出”, 并将在土地勾出后规定期限内组织招标拍卖, 提出 “勾地” 的开发商必须参加竞价 (报价不得低于其申请时的底价), 若拍卖达不到政府预期价格, 土地管理部门有权不出售, 可留作下次拍卖, 直至等于或高于政府预期价格为止。 
审查后, 多数低收人家庭一旦获得 “公租房”, 几乎就要一 直住下去, 除非在家庭收人增长后通过资助置业计划或于私 人市场购买楼宇后搬离。尽管各类资助出售居所可作为公屋 的 “置业阶梯”, 但各类资助出售居所均有转让限制。根据 房屋条例, 相关住户不仅有居住年限的限制, 特别是须先向 政府补缴地价后, 以解除转让限制, 才可将房屋在市场上出 租或转让。以居屋为例, 香港补缴地价并非按当初购人房屋 时的地价计算, 而是按现时地价市值计算 ${ }^{1}$ 。由于地价升幅 巨大, 补地价数额以数十万, 甚至百万港元计, 很少居屋住 户能在市场自由放售, 因此买卖十分稀疏, 导致居屋流通性 极低 ${ }^{[24]}$ 。为促进公营房屋的流通, 政府自 1997 年起推动 “居 屋第二市场”, 居屋住户可无需缴付补价, 直接在居屋第二 市场上售于具有资格的人士, 但买方须承担将来补缴地价的 责任。1998 年推行的 “租者置其屋计划” 转让限制与居屋 类似。因此, 如付不起巨大的补地价差额, 公营房屋住户可 能被困终身。

近年随着地价持续上涨, 补地价差额有增无减, 部分居 屋单位在计算补地价后的价格甚至已超越私人住宅的价格, 因此居屋转手的可能性日益泪茫。对于经济学家而言, 严 格设限导致了公营房屋在经济上的明显低效, 因为土地既 已兴建缺少市场机制的公营房屋, 他人也就无法再用, 土 地无法充分发挥效益, 经济学者称为资源错配所造成的 “效 率损失” (efficiency loss) ${ }^{[24]}$ 。殷伟宪发现在公屋计划每花 费 1 元, 租户只受益其中的 $0.61 \sim 0.75$ 元, 其余的 $0.25 \sim 0.39$ 元却因资源错配而遭到浪费 ${ }^{[25]}$ 。王于渐估计, 公屋计划每 年经济损失约为香港本地生产总值的 $0.5 \% \sim 1 \%{ }^{[26]}$ 。很多国 家与地区的实证研究皆指出, 类似香港的公屋计划是相当
低效和浪费的 ${ }^{[27,28]}$ 。

由于公营房屋主要建设地点在新界新市镇（新界公营 房屋约有 66 万套, 占全港总数约 $57 \%$ ), 居住于新界的公 营房屋人口约有 180 万之多, 但较佳的工作机会和公共配 套大多位于港九。由此, 公营房屋无形中抬高了新市镇居 民和家庭发展的代价。公营房屋计划失当的潜在社会成本, 包括所损失的发展机会和各种代价至今未得到充分的认

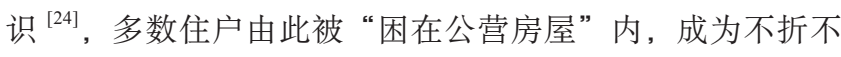
扣的“房奴”。

\section{3 “双元城市” 格局中的 “悲情市镇”}

尽管早前香港被赞誉为众多中低收人家庭解决了住房问 题, 但社会结构及其空间隐患早就 “隐藏” 在庞大的公屋计

表 12003 -2013 年香港各类房屋数量及居住人口

\begin{tabular}{|c|c|c|c|c|c|c|c|c|c|}
\hline \multirow[b]{2}{*}{ 房屋类型 } & \multicolumn{3}{|c|}{2003 年 } & \multicolumn{3}{|c|}{2008 年 } & \multicolumn{3}{|c|}{2013 年 } \\
\hline & $\begin{array}{c}\text { 房屋 } \\
\text { 数量 } \\
\text { (万套) }\end{array}$ & $\begin{array}{c}\text { 居住 } \\
\text { 人口 } \\
\text { (万人) }\end{array}$ & $\begin{array}{l}\text { 人口 } \\
\text { 比例 } \\
(\%)\end{array}$ & $\begin{array}{c}\text { 房屋 } \\
\text { 数量 } \\
\text { (万套) }\end{array}$ & $\begin{array}{c}\text { 居住 } \\
\text { 人口 } \\
\text { (万人) }\end{array}$ & $\begin{array}{l}\text { 人口 } \\
\text { 比例 } \\
(\%)\end{array}$ & $\begin{array}{c}\text { 房屋 } \\
\text { 数量 } \\
\text { (万隹) }\end{array}$ & \begin{tabular}{|c|} 
居住 \\
人口 \\
(万人)
\end{tabular} & $\begin{array}{l}\text { 人口 } \\
\text { 比例 } \\
(\%)\end{array}$ \\
\hline $\begin{array}{l}\text { 公营永久 } \\
\text { 性房屋 }\end{array}$ & 108.2 & 337.2 & 50.1 & 111.9 & 329.8 & 47.4 & 116.4 & 329.2 & 45.8 \\
\hline $\begin{array}{l}\text { 公共租住 } \\
\text { 房屋 }\end{array}$ & 68.5 & 209.3 & 31.1 & 72.2 & 203.9 & 29.3 & 77.2 & 210.6 & 29.3 \\
\hline $\begin{array}{l}\text { 资助自置 } \\
\text { 居所 }\end{array}$ & 39.7 & 127.9 & 19.0 & 39.7 & 125.9 & 18.1 & 39.2 & 118.6 & 16.5 \\
\hline $\begin{array}{l}\text { 私人永久 } \\
\text { 性房屋 }\end{array}$ & 127.9 & 330.5 & 49.1 & 139.9 & 361.8 & 52.0 & 148.4 & 385.9 & 53.7 \\
\hline 临时房屋 & - & 5.4 & 0.8 & - & 4.2 & 0.6 & - & 3.6 & 0.5 \\
\hline 合计 & 236.1 & 673.1 & 100 & 251.8 & 695.8 & 100 & 264.8 & 718.7 & 100 \\
\hline
\end{tabular}

资料来源 : 根据各年香港统计年刊整理

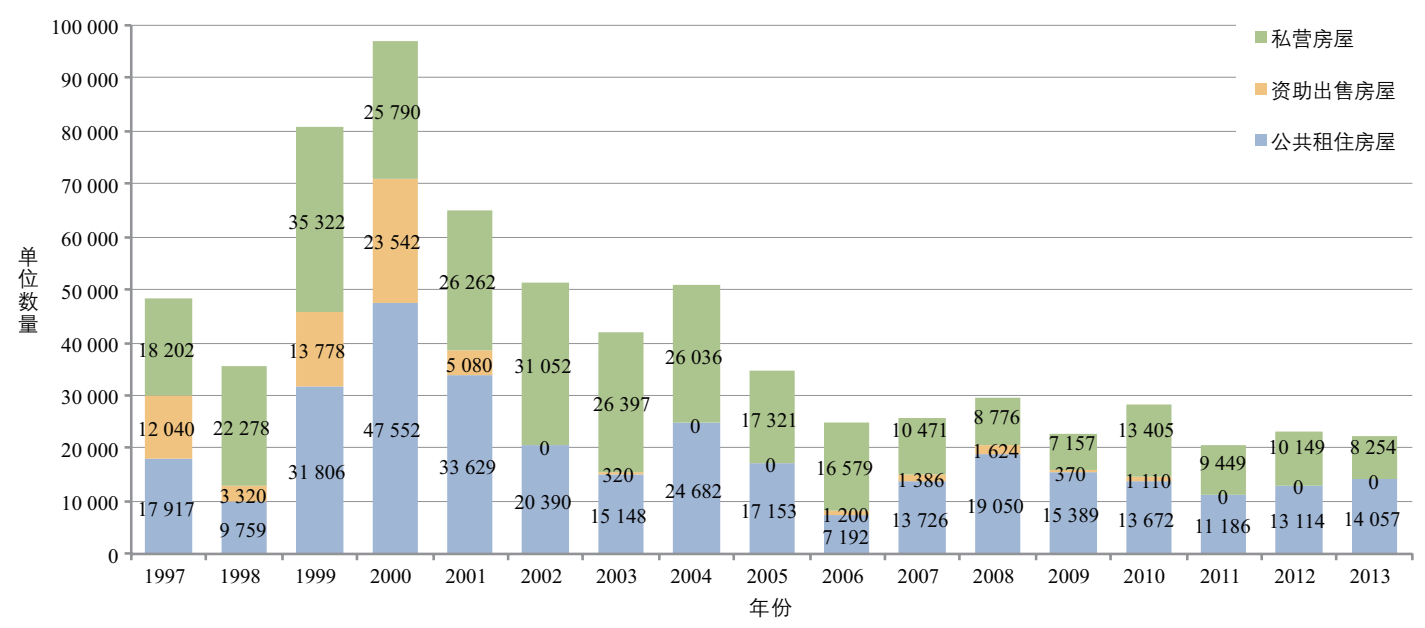

图 2 1997-2013 年新建成的香港房屋数量

资料来源 : 根据各年香港统计年刊绘制

(1) 补价的计算公式是: 补价 $=$ 补价时的评定市值 $\times($ 当时市值 - 当时定价)/当时定价。 
划之下。随着 1980 年代以来香港实体经济逐步北移至珠三 角地区，以金融、地产等为主的服务业逐步在 1990 年代开 始占据香港经济的主导地位, 而以金融等为主的资本操控致 使香港城市空间资源呈现不公平的分配劣境 ${ }^{[29]}$ 。香港的基 尼系数高达 0.537 , 居发达经济体之首, 贫富分化极为严重, 香港已彻底沦为 “双元城市” ${ }^{[30]}$ 格局 : 市区中心有无限的潜 能与资源投人，房地产市场无比多热；城市边缘的新市镇则 是低收人群体的聚集地, 不仅被排斥在城市经济的发展之外, 更被排斥在社会与文化生活之外 ${ }^{[29]}$ 。

回顾 1970 年代, 港府为兴建大规模的公屋惟有在城市 边缘开辟大块可建设用地, 新市镇才得以兴建。早期的新 市镇除了兴建住宅外, 还会划出工商业区, 目标是使这些新 市镇能 “自给自足”。但在发展实践中, 除离市区较近的荃 湾、葵青等少数新市镇能享受到与市区共享就业及配套服务 的好处外, 绝大多数新市镇的发展由于未达到 “自给自足” 而备受批评 ${ }^{[1]}$ 。一方面, 惟有房委会等有建屋计划, 但其他 政府部门并没有相关措施与政策吸引企业入驻以扩大就业机 会, 导致新市镇就业机会严重不足, 迫使劳动人口花费大量 的时间至市区就业, 造成较大的社会和经济损失 ${ }^{[31]}$ 。另一方 面, 新市镇过于注重公屋, 政府未能提供足够的设施配套与 服务, 从而对商家和中高收人者愈加缺乏吸引力, 进一步加 剧了新市镇低收人人群的社会隔离 ${ }^{[32,33]}$, 使得这些急促发展 起来的新市镇构成了社会学家所谓的 “社区的迷失” (loss of community) ${ }^{[34,35]}$ 。

在偏远的天水围、屯门、东涌等新市镇, 逐渐聚集着大 批低收人的市民及新移民。这些低收人社区持续传出负面新 闻诸如青少年暴力、吸毒、犯罪等, 更严重的是家庭伦常惨 剧 ${ }^{[29]}$ 。以天水围为例, 自 1990 年代开始建设新市镇时, 还 规划有一定居屋及 “夹心阶层” 房屋, 但伴随着亚洲金融危 机影响, 多数的居屋和 “夹屋” 被迫取消, 改建为接收低收 人家庭的租住公屋。在天水围 28 万人口中, 居住在公屋中 的人口比例高达 $85 \%$ 。天水围也由此成为香港内地新移民最 多, 失业人口最多, 低收人贫困人士最多, 单亲家庭最多, 独居长者最多和青少年问题最多的新市镇 ${ }^{[36]}$ 。由于就业机 会稀少, 且公共交通不便与费用较贵 (从天水围去往香港其 他地方只有一条港铁线, 乘港铁线至中环市中心单程车费约 20 港元), 天水围低收人居民无力承担外出交通费用, 不少 家庭长期依赖失业综合援助。同时, 也因为商业及公共设施 严重缺乏, 天水围不仅承受着不菲的物价, 也缺乏相应的娱 乐与休闲场所, 甚至无处就医。在失业、贫穷、孤独等问题 的影响之下, 发生了一宗又一宗震惊社会的家庭伦常惨剧, 赤裸裸地显示了天水围根本不是一个 “可居住” (habitable) 的地方 ${ }^{[29]}$ 。

\section{4 当前香港公营房屋政策的挑战}

近年来, 随着香港私人住宅价格的不断上涨以及公屋轮 候人数的明显增长, 在社会团体及民众呼声的普遍压力下, 特区政府已部署加大公营房屋建设计划, 居屋也由 “无限期 搁置” 到重新启动, 而围绕着香港公营房屋政策的争论也不 断升温。总体而言, 香港公营房屋面临着人口持续老化、“实 物” 供给滞后与经济发展难以匹配等挑战, 香港公营房屋政 策正处于进退维谷的困境。

\section{1 人口持续老化对既有公营房屋的挑战}

经过半个多世纪的沉淀, 香港公营房屋住户结构也出 现了明显的变化。一方面, 由于单身家庭不断增多, 为使公 屋能 “屋尽其用”, 面积少于 $40 \mathrm{~m}^{2}$ 的小型单位比例逐步递 增。截至 2014 年 3 月, 公屋中 $40 \mathrm{~m}^{2}$ 以下的单位占比高达 $81.9 \%$, 而居屋中 $50 \mathrm{~m}^{2}$ 以下单位也占一半以上, 三居室的 公屋于 2007 年停建。由于面积所限, 居住人数也受到较大 的限制。另一方面, 为避免缴纳额外租金甚至迁出, 住户往 往选择让子女搬离, 由此也妨碍了家庭几代同住或就近居住 的安排。此外, 香港房委会自 1979 年实施了高龄人士优先 配屋计划, 两名或以上有亲属或无亲属关系的 58 岁或以上 长者同意一同居住, 即可分配一个公屋单位, 也无形中增加 了老年人在公屋居住的比例 ${ }^{[37]}$ 。

同时, 如前文所述, 由于转让限制造成公营房屋流动 性极差, 也导致公营房屋租住人口老龄化趋势愈加明显, 其老龄人口的比例大大高于全港水平。与许多其他国家及 地区类似, 香港公屋中的主要租户从过去的技术工人群体 逐渐转向非技术工人。中高收人家庭越来越少, 而低收人 家庭比例逐渐提高。公屋成为老人、单身人士、穷人等经 济弱势群体的主要住房选择 ${ }^{[38]}$ 。自 2006 年开始, 香港公 屋中 $20 \%$ 的人口超过 60 岁。2 011 年, 香港独居及二老长 者住户有近半数 $(46.4 \%)$ 居于公屋, 并有三成长者生活在 贫穷线以下。

因此, 公营房屋政策在某种程度上也被社会與论评为 老人聚居的 “帮凶”, 隐含了香港公营房屋不断积累的结构 性问题。随着公屋中老人居住人口的不断增长, 尤其那些 在早期建屋计划下兴建的老化屋村, 已引起了多种 “老人 村” 问题, 如维修管理难以应对、健康及家居照顾不足、 医疗及长者康乐设施短缺、贫困以及社会排斥等问题。显 然, 香港公屋人口老化是一个不能回避的重要问题。但目 前香港房屋政策还未全面正视人口老化所带来的系列影响, 而如何积极地回应老龄化的需求, 是香港公屋政策面临的 较大挑战。 


\section{2 “补砖头” 惯性对抗房地产周期的挑战}

随着市民置业难度的不断加大, 呼吁政府加大公营房屋 供给的呼声与日俱增, 近年来特区政府的施政报告也提出一 系列增加土地供应的措施, 逐步加大公营房屋供给数量, 但 这种以住房实物建设供给的房屋政策, 已越来越明显地暴露 出其根本性的缺陷。由于香港经济高度开放, 在全球化的影 响下, 香港房地产不单取决于内部供求关系, 也受到全球金 融和资本流动的巨大影响。由于香港自 1983 年起用联系汇 率将港元与美元挂钩, 香港的商业周期深受美国利率和市场 波动的影响。近年来的港币贬值与按揭贷款近乎 “零利率” 进一步助推了房价欮升。因此, 香港房地产市场在全球化的 影响下有较大的不确定性, 深受无法预见的偶发性全球因素 所牵制, 楼市价格可能 “瞬息万变”。

吊论的是, 特区政府房屋政策依然固守在以 “补砖头” 资助来对抗房地产周期。由于市场反应在前、政府应变在 后, 靠对市场的预测和计划来抵消房地产周期波动的能力 十分有限。在政府 “认知滞后” (recognition lag)、“决策 滞后” (decision lag), 以及政策贯彻执行的 “落实滞后”

（implementation lag）的现实情境下 ${ }^{[24]}$, 既定的土地与房屋 政策到实施时其成效已变得十分难料, 因此时的经济环境已 不能同日而语。例如, 香港大型土地开发及房屋建设从研究、 规划、设计到土地平整、基建及房屋建设共历时 10 余年

(图 3), 至于在已发展土地上对个别用地进行开发, 也须 经相关评估、咨询、规划或土地清理等程序, 视用地情况不 同也要耗时数年不等。由此, 香港的实物房屋供给已很难适 应不断变化的社会经济环境。而当社会经济环境已出现急剧 转变, 房屋政策还是以 “不变应万变” ${ }^{[38]}$ 。因此, 固有的公 营房屋 “补砖头” 计划, 只会加深多年来依赖 “实物资助” 积累的问题 ${ }^{[24]}$ 。

从全球范围来看, 世界各经济体在住房领域的角色也在 经历迅速的变化。1980 年代以来, 在完成战后存量住房缺 口后, 发达国家与地区已普遍从大规模提供 “砖头和灰泥”

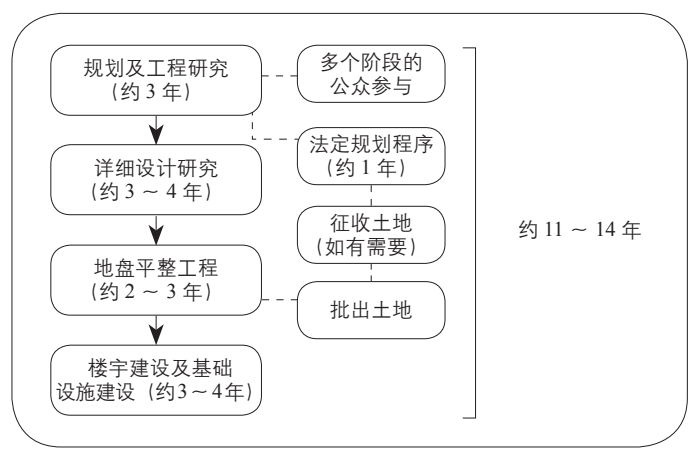

图 3 香港大型土地开发及房屋建设的主要流程与年限 资料来源 : 参考文献 [42]
的住房 “实物”, 逐步过渡到近年来更为常见的鼓励租户购 买租住居所与提供补贴的方式, 提高住房自有率 ${ }^{[40,41]}$, 其趋 势是由补助 “房屋生产者” 的资助方法转向辅助 “住房消费 者” 的资助方法 (consumer-subsidy approach), 使低收人家 庭直接从市场租买房屋 ${ }^{[13]}$ 。与香港拥有庞大公共房屋系统 类似的新加坡, 也在 1970 年代推动 “组屋” 的商品化, 所 有住户都可以选择租住、自置或先租后买, 住满五年后可在 公开市场上出售, 且无需补缴地价, 转手基本上不受限制 ${ }^{[1]}$ 。 当前新加坡仅 $8.6 \%$ 家庭是组屋租户，有 $73 \%$ 家庭购买了组 屋, 加上私人于市场购买的住房, 新加坡居民的住房自置率 高达 $90 \%$ 以上，与香港 “尾大不掉” 的公营房屋规模迥异。

\section{3 “泛政治化”约束下的房屋政策挑战}

尽管在新时期以 “补砖头” 性质为主导的公屋供给已难 以适应全球化时代香港社会经济的发展实际，但香港楼价的 日益攀升致使社会对加大公营房屋供给的期望陡升, 以至于 形成强大的政治诉求, 而与之相应的争论与冲突也屡见不鲜, 房屋政策也变得越来越 “泛政治化” ${ }^{[15]}$ 。以居屋为例, 专业 团体、社会学界及工会等民生派的观点认为, 由于房屋市场 价格波动很大, 一旦楼价刹升, 不少中产阶层既不能人住为 低收人阶层提供的公屋, 又无法在私人市场上租买价格高昂 的住房, 由此, 中产阶层将被排除于房屋系统之外 ${ }^{[20]}$ 。重新 建设居屋不仅可使楼市降温, 避免发展商操控楼市, 而且也 有利于房委会的收人, 以加大公屋的兴建效率, 有助于公屋 的流转。

而以自由主义经济学家、发展商等为主的市场派观点认 为, “居屋计划”已完成了历史使命, 政府应着重兴建出租 公屋以解决低收人市民的居住问题，为中等收人居民提供住 房不是政府的责任，居屋被视为政府对私人市场的干预与不 合理介人, 政府由此被批评为扮演发展商的角色 ${ }^{[20]}$ 。从香 港回归前后至今，有关公营房屋政策争议一直 “如火如茶”, 在立法会上的辩论也异常激烈。在各类团体的政治诉求裹挟 下, “头痛医头、脚痛医脚” 成为香港回归后房屋政策的生 动写照。

随着香港经济的不断发展, 住房物业早已成为香港居 民投资保值的重要工具。有房者可借助物业的增值与香港 经济发展保持同步, 而无楼者在某种程度上已与香港经济 发展脱节。不同阶层的经济差距日益扩大, 进一步加大社 会和政治上的分化 ${ }^{[24]}$ 。由于公营房屋计划不仅对香港家庭 影响深远, 而且延伸至香港社会经济的整个面向, 也令许 多本属房屋政策的技术问题演变为政治问题。因房屋政策 而产生的请愿、静坐，甚至暴力对抗也经常出现，房屋问 题也被列为区议会及立法会等引进直选以来的重要选举议 
题 ${ }^{[43]}$ 。而与土地开发与房屋建设有关的发展计划也在此形 势下受到各式各样的政治角力与牵制下裹步不前, 寸步难 行。在 “泛政治化”的影响下, “议而不决、决而不行”成 为制约香港推动土地开发与房屋供给的重要挑战, 但现实采 热的楼市环境也不容许政府相关计划一拖再拖。然而由于日 益不确定的市场环境, 即使当前新的“补砖头”计划能顺 利推行, 但 “计划赶不上变化”, 也很有可能会重蹈“八万五 计划” 的覆辙, “退后一步是泥淖, 往前一步也可能是陷阱”, 裹挟在日益“泛政治化”的香港房屋政策正面临进退维谷 的困境。

\section{5 结语}

总体而言, 经过半个多世纪的发展与不断演进, 香港 成为世界上公营房屋规模最为庞大的城市- 300 多万人口 居住于 100 多万套公屋及居屋之中, 一度被誉为解决城市 中低收人市民居住问题的成功范例。但在香港庞大的公屋 体系中, 一方面, 由于土地出让及开发管理等有关的土地 收人是香港财政收人的重要来源, 有关严控土地供应与 “稳 定楼市”等助推的高房价，也常被批评为政府与“地产霸 权” 共谋而形成的 “畸形增长机器” 下的产物, 并在全球 金融资本与自由市场的影响下变本加厉, 进一步加剧房屋 供需的失衡。

而另一方面由于早期公营房屋居住条件恶劣而需推倒重 建, 以及公营房屋存在严苛的转让限制, 不仅导致可观的资 源浪费与 “社会效率损失”, 流动性极弱也使大量居民被 “捆 绑” 在公营房屋内成为另类 “房奴”, 造就了香港约半数家 庭失去置房能力 ${ }^{[44]}$, 而未置业家庭基本与香港经济发展相脱 节, 加深了社会阶层差距的扩大与社会对立情绪, 由此衍生 的“双元城市”与 “悲情市镇” 不能不说是房屋政策惯性下 的“副产品”。

因此, “大规模的公营房屋计划不仅界定了政策方面的 选择，更限制了这种选择” ${ }^{[45]}$ ，导致香港房屋政策在“政 府提供更多公共住房和市场提供更多商品住房”之间艰难 地摇摆。然而, 一方面, 随着公屋居住人口的持续老龄化, 尤其是早期建屋计划下兴建的屋村已面临后续维护与应对 老龄化需求不足的严峻挑战；另一方面，持续以 “补砖头” 性质为主导的香港实物公屋供给已越来越与国际主流趋势 不相适应，而依赖“滞后效应”明显的“补砖头”以对抗 日益不稳定的房地产市场无异于缘木求鱼。然而政府也只 能在庞大公屋体系的惯性约束下, 疲于应对社会各界对于 房屋的诉求。香港公营房屋所积累的结构性问题正面临进 退维谷的困境，如何突破既有的惯性依赖，是特区政府亟 需面对的重大挑战。UPI

\section{参考文献}

[1] 王于渐. 香港与内地公营房屋政策 [EB/OL]. [2011-9-23]. http://www. wangyujian.com/?p=1132.

[2] Sit V F S. Post-war Population and its Spatial Dynamics[M] // Victor F S Sit, ed. Urban Hong Kong. Hong Kong: Summerson Eastern Publishers Ltd, 1981: 2-25.

[3] 冯邦彦.香港地产业百年 [M]. 香港: 三联书店, 2001 .

[4] 蓝逸之. 新自由主义下的香港治理: 空间、尺度与策略 [M]. 台北: 政 大出版社, 2014

[5] Drakakis-Smith, David W. High Society: Housing Provision in Metropolitan Hong Kong, 1954 to 1979-A Jubliee Critique[M]. Hong Kong: Centre of Asian Studies, University of Hong Kong, 1979: 96.

[6] 杨汝万. 房屋政策 [M] // 刘兆佳, 编. 香港二十一世纪蓝图 . 香港: 中 文大学出版社, 2000: 195-205.

[7] 林云峰, 聶志. 规划与空间配置 [M] // 杨汝万, 王家英, 合编. 香港公 营房屋五十年：金禧回顾与前瞻。香港：中文大学出版社, 2003: 43-60.

[8] Morris J C. Administration and Finance of Public Housing[M] // Luke S K Wong, ed. Housing in Hong Kong: A Multi-disciplinary Study. Hong Kong: Heinemann Educational Books(Asia)Ltd., 1978: 55-71.

[9] Chiu Rebecca L H. "Housing Intervention in Hong Kong: From Laissez Faire to Privatization" , 25 years of Social and Economic Development in Hong Kong[M]. Hong Kong: Centre of Asian Studies, University of Hong Kong, 1994: 336-56.

[10] Yeh Anthony G O, Peter K W Fong. Public Housing and Urban Development in Hong Kong[J]. Third World Planning Review, 1984, 6(1): 79-94.

[11] Wang Liang-huew, Yeh Anthony G O. Public Housing-led New Town Devlopment: Hong Kong and Sigapore[J]. Third World Planning Review, 1987, 9(1): 41-63.

[12] Castells M, Goh L, Kwok R Y W. The Shek Kip Mei Syndrome: Economic Development and Public Housing in Hong Kong and Singapoer[M]. London: Pion Ltd, 1990.

[13] 赵丽霞. 房屋政策趋势的分析 $[\mathrm{M}] / /$ 杨汝万, 王家英, 合编. 香港公营 房屋五十年: 金禧回顾与前瞻. 香港: 中文大学出版社, 2003: 221-242.

[14] 李思名, 余赴礼. 香港都市问题研究 [M]. 香港: 商务印书馆, 1987.

[15] 杨汝万, 邬满海。总论 $[\mathrm{M}] / /$ 杨汝万, 王家英, 合编. 香港公营房屋 五十年: 金禧回顾与前瞻.香港: 中文大学出版社, 2003: 1-18.

[16] 罗天吴. 香港模式的瓶颈 [EB/OL]. [2010-12-6]. http://www.ftchinese. com/story/001035881?full=y.

[17] 聂日明. 自由香港的不自由经济 [EB/OL]. [2015-3-16]. http://www. ftchinese?.com/story/001060945??page=1.

[18] Hong Kong Concumer Council. How Competitive is The Private Residential Property Market? [EB/OL]. [1996]. http://www.consumer.org. hk/website/wrap chi2/hse9607/ANNEX/A9 C.HTM.

[19] 潘慧姻. 地产霸权 [M]. 北京: 中国人民大学出版社, 2011 .

[20]李健正. 居者有其屋计划及其持续需要 $[\mathrm{M}] / /$ 杨汝万, 王家英, 合 编。香港公营房屋五十年：金禧回顾与前瞻。香港：中文大学出版社, 2003: 243-264.

[21] Haila Anne. Real Estate in Global Cities: Singapore and Hong Kong as Property States[J]. Urban Studies, 2000, 37(12): 2241-2256.

[22] Lee J. Urban Policy[M] // Wai-Man Lam, Percy Luen-Tim Lui, Wilson Wong and Ian Holliday, eds. Contemporary Hong Kong Politics: Governance in the Post-1997 Era. Hong Kong: Hong Kong University Press, 2007: 223-242.

[23] 李健正. 社会政策视角下的香港住房政策: 积极不干预主义的悖论 [J]. 公共行政评论, 2009, 2(6): 1-23.

[24] 王于渐. 香港长远房屋策略和港人港地 [M]. 香港: 中华书局, 2013 .

[25] Yan W H. Efficiency in the Distribution of Hong Kong Public Housing Resources: 70's-90's[D]. Ph.D. Thesis, University of Hong Kong, 2000.

(下转78页) 